\title{
Traditional Positioning Technology and Fishermen's Marine Knowledge in Fishing Activities: A Case Study of the Stationary Fishing Net and the Gillnet in Yinggehai District
}

\author{
YU, Mingqi \\ Graduate School of History and Folklore Studies, Kanagawa \\ University \\ Publication Information: \\ Received 31 August 2018, Accepted 29 November June 2018, Available online 31 December 2018 \\ doi: 10.21463/jmic.2018.07.2.11
}

\begin{abstract}
Based on field surveys of traditional positioning technology used in stationary fishing net and gillnet operation in Yinggehai District, Hainan Province of China, and combined with research of available literature, this paper gives a brief analysis of the methods used and the knowledge required to determine location in fishing activities before the common use of GPS.
\end{abstract}

Keywords

positioning technology, stationary fishing net, gillnet, marine knowledge

\section{Introduction}

The town of Yinggehai $\left(108.73^{\circ} \mathrm{E}, 13.5^{\circ} \mathrm{N}\right)$ is located in the southwest of Hainan Province. It belongs to Ledong Li Autonomous County. It neighbors the Beibu Gulf Rim in the west and north, and it sits with its back to Jianfeng Peak while it faces Vietnam across the sea. The town covers a total area of 240,000 square kilometers with a sea area of 5.86 million hectares and a water depth of 80 to 200 meters. There are four 'natural villages' and seven neighborhood committees. The town of Yinggehai is a fishing town with little farmland and more than 300 fishing boats. Fishermen are 
also engaged in other work when the fishing season finishes. Yinggehai has five major fishing operations and 23 different kinds of nets, including one type of traction net, eleven different types of gillnet, two types of stationary fishing nets, four types of fishing operations, two types of light fishing operations, one type of twisted net, one type of pull net, and three types of bag nets. This paper analyzes the traditional positioning technology and the marine knowledge of fishermen used in the stationary fishing net operations and gillnet operations in Yinggehai.

\section{The Stationary Fishing Nets}

A stationary fishing net is a net fixed at a certain position on the seabed. In literal terms, it is a method of fishing which involves catching fish in a net. According to Fu's Genealogy, Kui and Li migrated from the village of Shangsha, Qiongshan, to Yinggehai in the Kangxi Period (1662-1722). It is believed that they were the original inhabitants of this place, and they were the first to use stationary fishing nets. People call the sea area where Kui and Li operated this method 'Laofuluo'.

\section{(1) The Shape and Components of Stationary Fishing Nets}

The stationary fishing net in Yinggehai consists of a double-pile stationary fishing net. According to the dialect in Yinggehai, it consists of five parts as shown below, namely Qiang, Gen, Hei, $\mathrm{Bi}$, and Wang (net). The Wang is divided into the main net, Wangdai and Wangjiu.

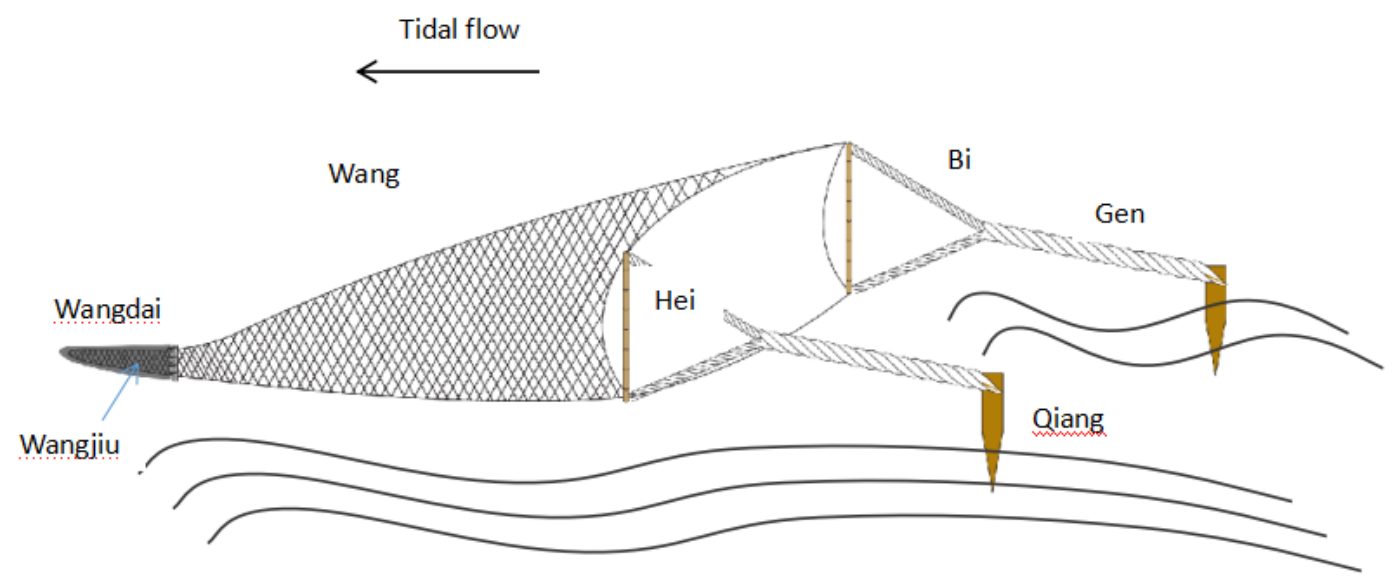

Fig 1. The Shape of Stationary Fishing Nets

Qiang: two piles are inserted into the seabed to fix the net. The piles, which are made of iron nowadays, were made of wood in the past. The size of the piles depends on the size of the net, and a larger net requires a relatively larger pile. The diameter of the piles is about $25 \mathrm{~cm}$, with a length of more than $200 \mathrm{~cm}$. 
Gen: these are the ropes that connect the pile and the net. According to the fishermen, ropes were made of straw and rattan before the 1970s. As people in Yinggehai did not plant rice, they bought straw from nearby villages. They also exchanged or purchased rattan from the Li-zu (Li ethnic people). After the 1970s, people began making rope from fiber.

Hei: this refers to the bamboo or plastic pipe used to fix the net. Two bamboo poles tied together are used to fasten the four corners of the net, forming the shape of a door. Generally, the bamboo is $6-10 \mathrm{~m}$ long, with a diameter of 8-10cm. People bought bamboo planted by the Li-zu and the fishing net would float aided by the buoyancy of the bamboo.

$\mathrm{Bi}$ : these are the ropes that connect the 'hey' and the 'gen'. There are two on each side, four in total.

Wang: the mesh of the net gradually becomes smaller from the opening to the interior. The fish are caught in a part called the Wangdai. To prevent the fish from escaping, fishermen would pull another net called Wangjiu in the Wangdai. Previously, the net was made of hemp, known locally as mountain hemp. It was made by pounding the hemp, drying it and then weaving it into a net. Recently, people have switched to using artificial fibers instead.

People use a special bark bought from the Li-zu to prevent decay of the net and rope. They use a pot to boil the bark until it becomes a red liquid, and the net and rope are placed into this solution. Dying the net and rope red helps the fight against decay.

\section{(2) The Use of Marine Knowledge: Flowing Water}

As part of this investigation, we must refer to 'flowing water' when talking about stationary fishing network operations. In local terminology, 'flowing water' refers to the change of currents and tides. It is said that 'flowing water' provides a continuous supply of fish, which evidently plays an important role in fishery. Although local fishermen were not trained to have a specialized knowledge of tidal matters, they acquired it as part of their practical activities and from the older generations. As a fisherman said about the monthly occurrences of 'flowing water':

'Flowing water' happens twice in a month. Each time, it lasts ten days, so it lasts twenty days in all. And there is no 'flowing water' in between those times, so the fishermen pull up their nets and prepare for the next activity. The 'flowing water' starts at different times in different months. The first day 'flowing water' starts is called 'new flowing' and the last day is called 'old flowing'.

According to the fishermen, as shown in Figure 2, if we assume that the 'flowing water' begins on the first day of a lunar month, then the first day to the tenth day is the first 'flowing water' and the sixteenth day to the twenty-fifth day is the next 'flowing water'. In this same period, there would be no 'flowing water' during the month from the eleventh day to the fifteenth day and the twenty-sixth day to the thirtieth day. The pattern and tendency of flowing water is weak-strongweak-nothing-weak-strong-weak-nothing. Therefore, the time that one can go fishing changes according to flowing time. When flowing water comes, the fishermen place the nets; when it is over, they draw the nets back. As for the changes in start time in different months, a fisherman wrote down from memory a local 'flowing water timetable' in the lunar calendar as shown in Figure 3. 


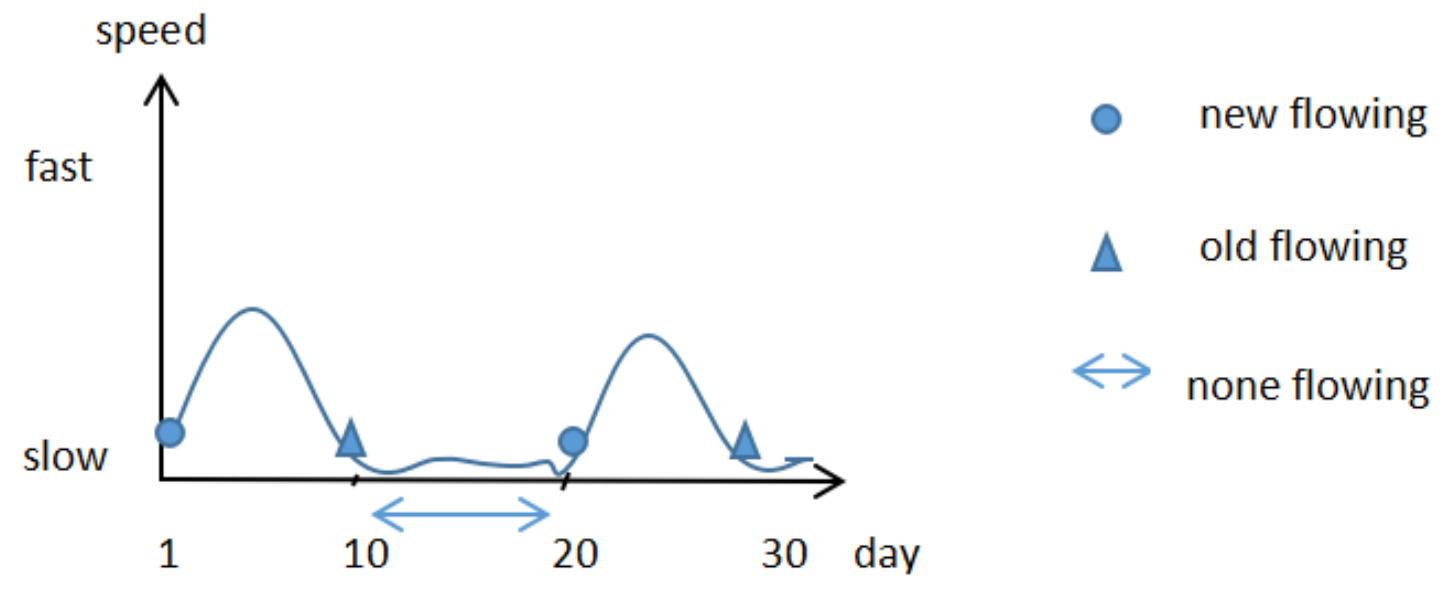

Fig 2. Flowing Water in a Lunar Month

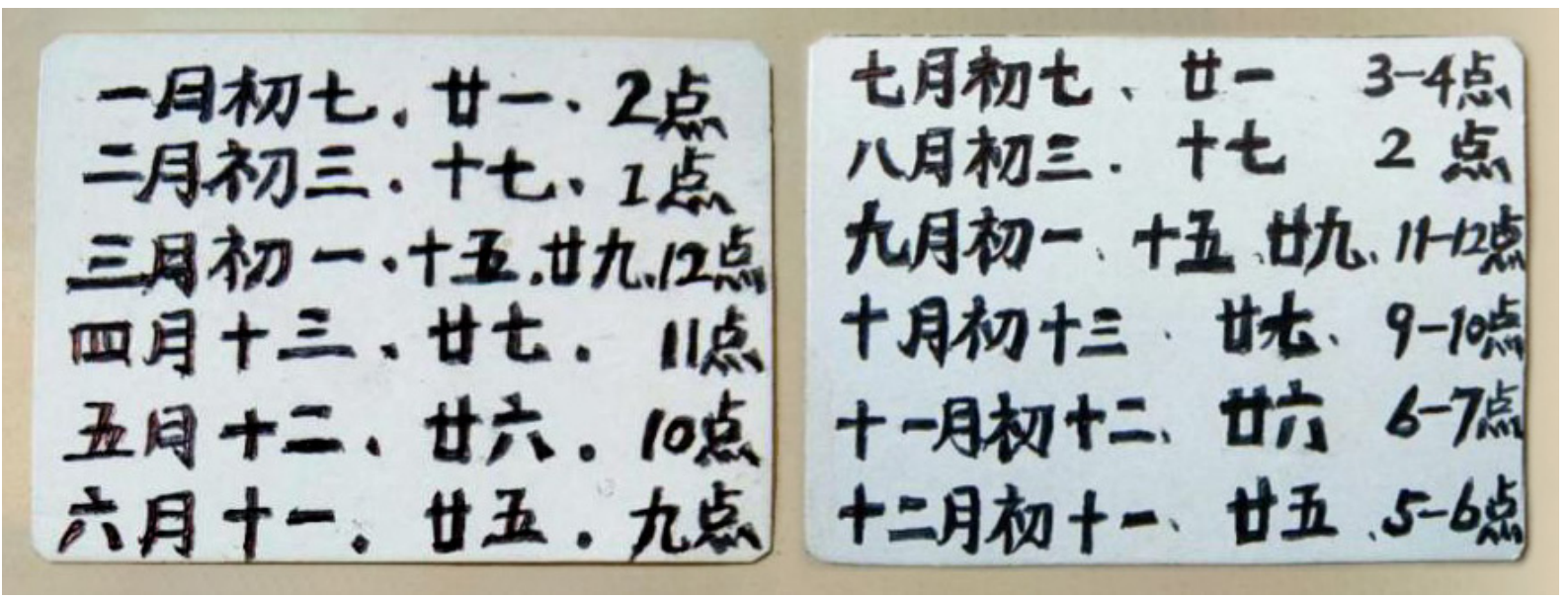

Fig 3. Flowing Water Timetable

The time of flowing water also changes from day to day. The fisherman said:

Generally, there are two 'flowing waters' in a day; one comes in the day time, the other comes in the nighttime. In the daytime, the 'flowing water' flows to the south and at night it flows to the north. Sometimes it only happens once. The time we fish depends on the time of the 'flowing water'. There is an hour between two flowing waters when the net will float. We must seize the exact time to draw in the net, or it will sink, whether we are too early or too late.

It can be seen that 'flowing water' is very important to the operation of the stationary fishing net. This is evident in two different ways: firstly, the monthly 'flowing water' cycle is crucial with regards to when to operate; secondly, the daily occurrence of 'flowing water' determines when to draw in the nets.

The most important aspect of this phenomenon is the local fishermen's knowledge of 'flowing water'. Some bibliographic records show interesting information. Firstly, Yazhou Zhi gives some recorded information on tides. Yazhou 
Zhi used to be called Zhong Zhi, which was written by Yuan Di, an official of Yazhou in 1900. It says, "The tides in the morning are 'chao', those in the evening are 'xi'. Bao Puzi says the water comes from the essence of the sun and the moon. A full moon brings a full tide. Tu Jing says that the regulation of the tides is certain. The tide in Qiongzhou is different from that in Jiang-Zhe because of their respective different land formations.

The literature shows that the tide in the Qiongzhou (Hainan) area is different from the tide in the Zhejiang area because of the different terrains of Qiongzhou and Xuwen. It notes that when the tide rises, it flows west, and when it falls, it flows east. The records are therefore different from the anecdotal evidence of the fishermen who said that the tide flows either north or south. A possible explanation is that Yazhou Zhi was written by local officials. Although it concerns the local history of the Yazhou area, the record of the tides is about the whole area of Hainan Province. Hainan Island is wide, so tides in different regions can be quite different. This book cannot represent the whole situation across the entire province.

The second piece of bibliographic information is the local document 'Chao Xi Zhu Yue Liu Shui Shi Ke Biao (Monthly Tide Table)'. It is a year-long record of the time and direction of 'water flow' every day. The record of the water from the first to the fifteenth day of the year in the lunar calendar is extracted below:

On the first and second days in the first month of the lunar year, the tide flows east from 3 a.m. to 5 a.m. and west from 11a.m. to 1 p.m. On the third and fourth days, the tide flows east from 5 a.m. to 7 a.m. and west from 1 p.m. to 3 p.m. On the fifth day, the tide flows west from 7 a.m. to 9 a.m. There is no tide on the sixth, seventh and eighth days. On the ninth day, the tide flows to the east from 7 a.m. to 9 a.m. and to the west from 3 a.m. to 5 a.m.

It can be seen that there are two 'flowing water' times on certain days, such as the first and second days. There is only one 'flowing water' on the fifth day. There is no 'flowing water' on the sixth, seventh and eighth days. This is quite similar to the tides mentioned by the fishermen. However, as regards the flow of the tide, the records are different from what the fishermen said. They think the tide flows to the north or south. The fishermen interviewed live in an area where the coastline follows a north-south line, but the coastline of the village of Xincun is east-west. So, this 'Chao Xi Zhu Yue Liu Shui Shi Ke Biao (Monthly Tide Table)' may record the tidal situation of Xincun village.

\section{(3) The Methods used to Locate Stationary Fishing Nets}

Generally, stationary fishing nets are laid out in offshore areas. A survey of fishermen shows that it is quite complex to find out the location of the nets without GPS.

Fisherman A's description about how to find stationary fishing nets is as follows:

We have a flashing light (the lighthouse) in Yinggehai. We had no technical assistance but our brains in the old days. If we go in this direction at night, we take a kerosene lamp and place it between the flashing light and the direction of travel. When we go forward, we aim at the lamp above and the lamp below, in this way we can find our nets. If our route deviates, we can also locate the nets by the deviation angle. Another reference is the time we set sail. When we are sailing, we can estimate the distance through the time we spend. If there is 'flowing water' or it is flowing in the wrong direction, we need to adjust our route through the lamps. We rely on our brains, generation after generation.

Fisherman B's description about how to find stationary fishing nets: 
At night, we look at the lights on the land when we are not far from the coast. There are lots of lights on the land, and I choose one of them like the one in Gong Xia Tou because from there my nets are located in between the lighthouse and the lights. If my ship is not in the middle, we have to change route.

Fisherman C's description about how to find stationary fishing nets:

In fine weather, the stars and the moon are our navigators. From when the ship sets out, to the time after we have sailed for an hour, or two hours, the positions of the moon are quite different. In this way we can find our nets based on the moon's position, when there is no 'flowing water'. As to the stars, we generally refer to the Dipper. The method is quite the same as when we use the moon to locate the nets.

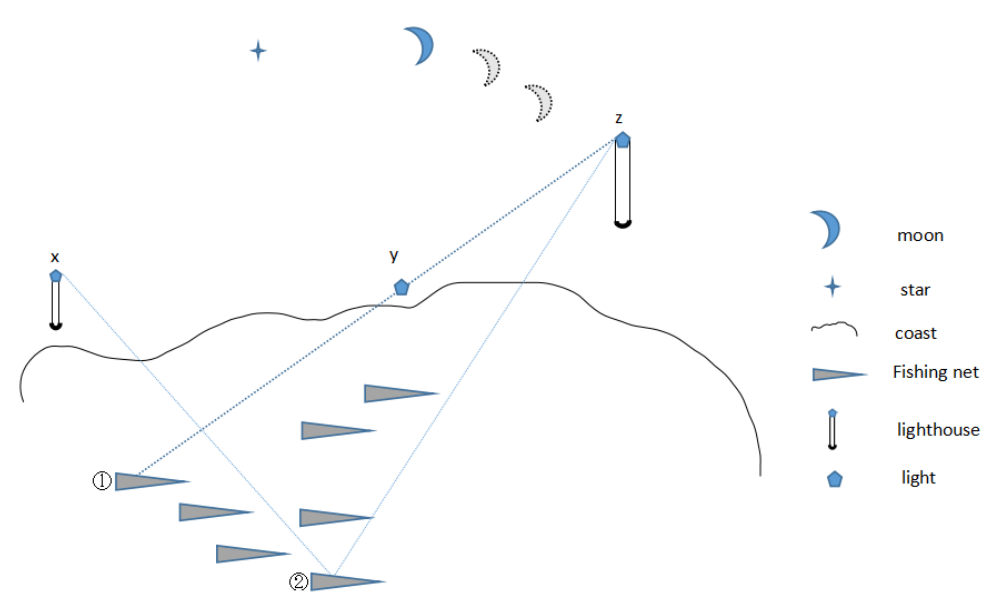

Fig 4. The Methods used to Locate Stationary Fishing Nets

According to the three fishermen, there are three ways of finding the stationary fishing nets. The first method is to sail along a straight line formed by two landmarks on the land, using the sailing time and the relative position to estimate the position of the fishing vessel. In Fisherman A's description, shown in Figure 4, he puts a light between the modern technology of the lighthouse and the nets on land near the shore. When he is sailing, he utilizes the line formed by the two lights and distance in sailing hours to find his nets.

Another method is to refer to the angle between the fishing vessel and two references on the land when sailing (triangulation). In the description of Fisherman B, shown in Figure 4, the nets form an angle with the reference light $y$ and the lighthouse $z$. Once you find the correct angle on the voyage, you will find the nets.

The last is to use the rules of celestial movement to find the nets. In the description of Fisherman C, when the fishermen start off, they observe the position of the moon and then take note of it once per hour until there is no 'flowing water'. They then depend on the moon's position to confirm the position of the net.

The three kinds of positioning methods mentioned above are accomplished by means of establishing reference markers. The choice of the reference varies with the position of the nets. At the same time, fishermen also mentioned that sometimes they are unable to find the nets due to the heavy waves and 'flowing water'. It means that the 'flowing water' may also influence their judgment. 


\section{The Gillnet}

The gillnet is a mode of fishing based on the condition of 'flowing water'. Fishermen put the nets into the sea and the net flows along with the ocean current. When fish swim into the mesh along the 'flowing water', they take the net in.

\section{(1) The Shape and Components of the Gillnet in Yinggehai}

The 'gillnet' mainly consists of floating rods, nets and lead blocks. The floating rods are made from bamboo. Fishermen insert the bottom of the floating rod into a concrete pipe when they are fishing. It is mainly used for marking and confirming the position of the fishing net in the sea. The lead blocks are used to increase the weight of the nets which helps the nets sink into the seabed. When fish swim into the mesh along the 'flowing water', fishermen draw the net in. Nets with different mesh sizes are used to capture fish of various sizes. The gillnet operation needs a certain seabed environment. For example, it cannot be placed where there are multiple reefs, because the nets could easily be cut in a rocky place.

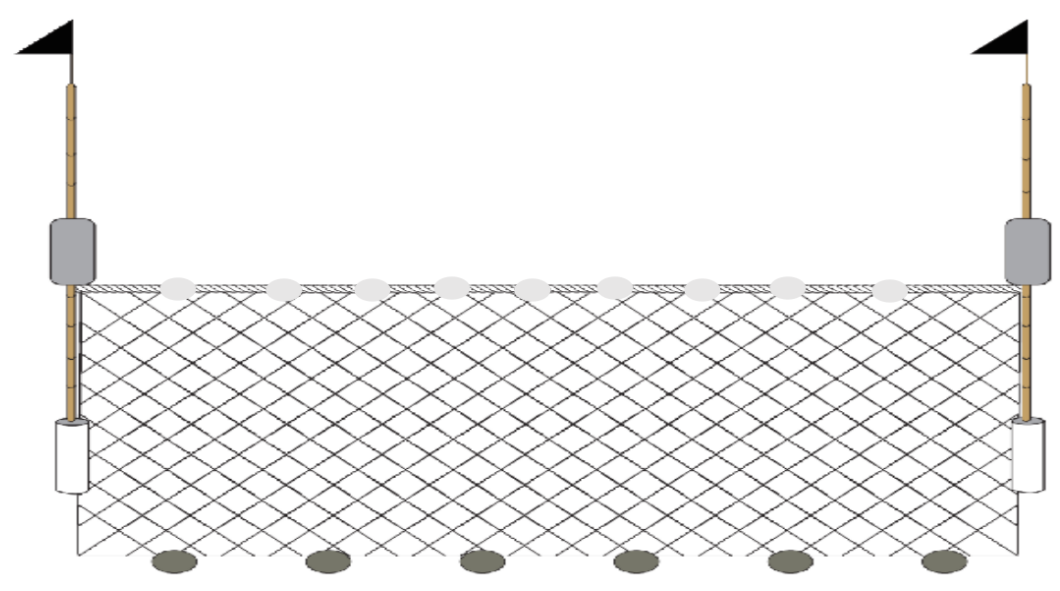

Fig 5. The Shape of the Gillnet in Yinggehai

Previously, the fishermen used a utensil called a 'Shi Shui Tuo' to confirm the seabed environment. They put it in the seabed to make sediment stick to it, and then they could determine whether the nets could be placed in that location depending on the type of sediment obtained.

\section{(2) 'Flowing Net' and 'Shi Shui Tuo'}

A Fisherman mentioned the following about 'Shi Shui Tuo':

We tie a large block of lead to a rope, and then we can test the depth of the water. The unit of depth is 'shou'. The depth of water varies from one shou, two shou to a dozen shou. We put the gillnet on the bottom of the 
seabed and then pull it out to observe the sediment. If there is no sand in the sediment, we can place the gillnet in that place. We use the sediment to determine the potential and the situation of the reefs in the seabed. If there is sand in the sediment it means reefs exist there, and in that case, we will sail on further. After sailing for about half an hour, we measure the place where we may put down the 'gillnet'. We can also use the mud to judge where we are. For example, if there is red sand, we know that we are on the east side of the small island. Different places, different sediments.

The 'Shi Shui Tuo', a tool mentioned by fishermen, is a lead block with rope, to measure the depth of the sea and to draw the sediment from the seabed. The gillnet needs to avoid reefs. If the sediment taken by 'Shi Shui Tuo' contains too much sand, it means there are reefs, and so the gillnet cannot be placed there. On the contrary, if it contains little sand but mud instead, it means the net can be placed there. Every half hour, the fishermen measure once to confirm the area where they can put out their nets. When sailing, the Shi Shui Tuo can also be used to determine the position of the ship in the sea. So, by observing the color and other elements of the sediment in the seabed, they can determine where the ship is.

Wen Chang Za Lu records:

Hong Lu Da Qing said: Previously, when the ambassador sailed to Gao Li, they used to use La Tuo to measure the depth of the sea. If the depth was more than 36 Tuo, then they could keep sailing.

Tian Xia Jun Guo Li Bing Shu records:

When sailing, if there is no island in sight, people always drop a cotton line (about 60 to 70 zhang [about 200 $\mathrm{m}$ l long) with a beef fat-smeared lead lump hanging from it into the bottom of sea. Then they pull it up to distinguish the color of earth brought out by the lead lump to know where the ship is. If nothing sticks to the lead lump, it is either too deep or too rocky to anchor.

Tai Hai Shi Cha Lu records:

Each vessel carries a rowing boat made from cedar for easier landing. Rowing boats come in and go out through the side of the vessel. It is named the 'shui xian men'. There are three kinds of anchorage, that is (primary) anchorage (also named jiang jun ding, but barely used), sub-anchorage and third anchorage. The depth of anchorages is in the tens of zhang. Before anchoring, people use the lead lump to test the depth of the sea. The length of rope attached to the lead lump is 60 to 70 zhang. If the rope cannot reach the bottom of the seabed, they cannot anchor there. The bottom of the lead lump is smeared with beef fat. It is used to make sand from the seabed stick to the lead lump, so that sailors can recognize where the vessel is.

Wen Chang Za Lu records that in the diplomatic mission to Gao Li, in the ocean voyage, sailors used 'La Tuo' to measure the depth of the seabed to keep the ship safe. Tian Xia Jun Guo Li Bing Shu records sailors using a lead lump to locate and guarantee the best place for anchoring. Tai Hai Shi Cha Lu records two usages of lead lump-one is to measure water depth, and the other is to make earth from the seabed stick to it for observation.

To summarize the information in the books mentioned above, the 'lead lump' played two direct roles, namely, to measure water depth and to provide a way to adhere the seabed sediment. It also has three important roles in terms of judging the safety of the vessel, determining the anchoring environment and establishing the vessel's location.

Comparing the above with the fishermen's description of 'Shi Shui Tuo', we can see that the usage is similar. The books have explained the role of 'Shi Shui Tuo' in navigation and the fishermen have explained its role in fishing activities and 
positioning operations. The explanations coincide with and complement each other. However, the two types of resources combined offer a better explanation of the usage of 'Shi Shui Tuo'.

\section{Conclusion}

In this paper, the author investigated the positioning methods used to operate stationary fishing nets and gillnets and analyzed the different elements of marine knowledge used by Yinggehai fishermen, including the wisdom passed down from preceding generations. Based on the anecdotes of the fishermen, in the old days without modern technological assistance, fishermen determined their location by looking at the seabed sediment, examining the 'flowing water', observing land signs, and celestial movements.

As shown in Figure 6, fishermen need to master and use a comprehensive environmental knowledge of the seabed, sea, land and sky to determine position in fishing activities. Although they have had no specialist training in marine science, fishermen in Yinggehai can still successfully conduct their jobs by relying on the experience of their ancestors and their own 'brains'.

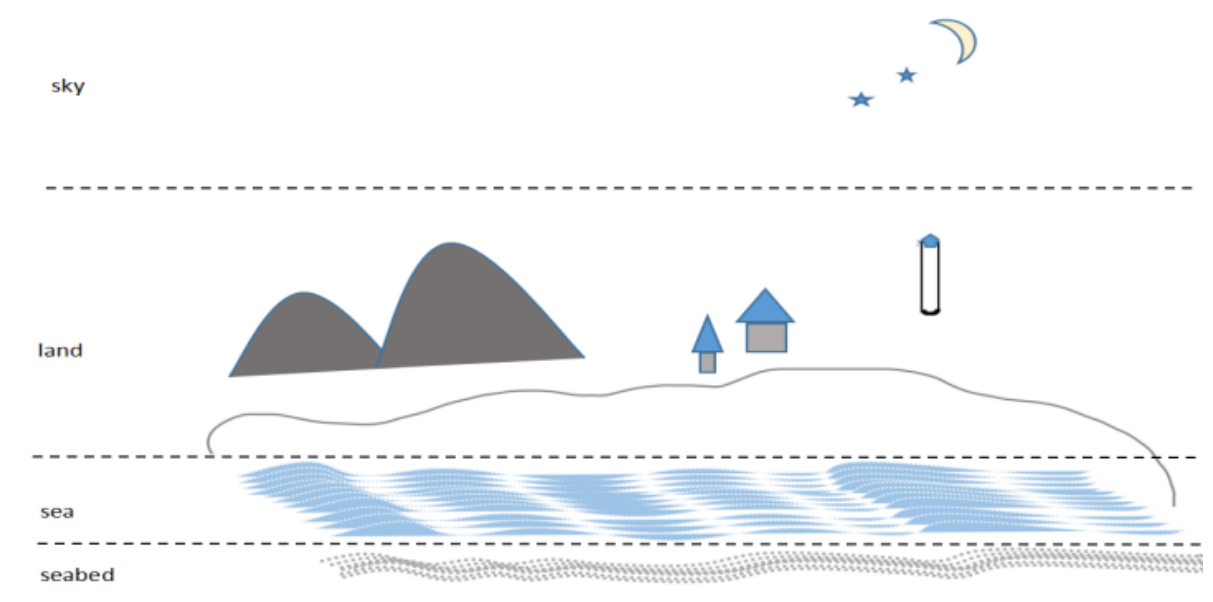

Fig 6. The Fishmen's Marine knowledge

At the same time, through a comparative study of the field investigation and documents in the Yinggehai District, it is evident that fishermen's awareness of marine knowledge and marine production in Yinggehai is a sort of progress from personal experience to a common understanding. Also, it is a process of passing this understanding from one generation to the next through various means.

There are three different ways of passing on this information-documents and written text, oral accounts, and tools. In the process of this information being passed on, it will be affected by different factors. The survey finds that with the introduction of modern technology, some old fishermen in the Yinggehai have begun to combine modern technology with traditional knowledge in their fishing activities. 
In the future, the author will conduct further study regarding how traditional marine knowledge exists in a modern scientific environment. The author will analyze different related factors based on an analysis of written documents, oral accounts, tools and other materials.

\section{References}

Gu, Y., 1956. Tian Xia Jun Guo Li Bing Shu, Yee Wen Publishing Company, Fujian.

Huang, S., 1985. Tai Hai Shi Cha Lu, Zhong Hua Book Company, Peking.

Lin, H., 2017. Traditional Navigation sounding Equipment 'qian chui', Fujian Wen Bo, Fujian.

Ming, Y., 1968. Daoguang Qiongzhou Fu Zhi, Cheng Wen Book Company, Taiwan.

Pang, Y., 1958. Wen Chang Za Lu, Zhong Hua Book Company, Peking.

Peng, D.,1988. History of Navigation in China, China Communications Press, Peking.

The Palace Museum, 2001. Qianlong Yazhou Zhi Lingshui Xian Zhi Changhua Zhi, Hainan Publishing Company, Hainan, p.135.

Wu, Z., 1939, Meng Liang Lu, The Commercial Press, Peking.

Yinggehaiqi Compilation Committee, 2014. Yinggehai Zhi, Nanhai Publishing Company, Hainan, p. 002.

Zhang, X., 1991, History of navigation science and technology in China, China Ocean Press, Peking. 